\title{
S5ynthesis
}

International Scientific Conference of IT and Business-Related Research

\section{PRIMENA SISTEMA MERENJA PERFORMANSI U JAVNOJ ORGANIZACIJI}

\section{THE USE OF PERFORMANCE MEASUREMENT SYSTEMS IN PUBLIC SECTOR ORGANIZATION}

\author{
Zoran Stevanović ${ }^{1}$, Lazar Dražeta ${ }^{2}$ \\ ${ }^{1}$ Auto-moto savez Republike Srpske, Banja Luka, Republika Srpska, BiH \\ ${ }^{2}$ Univerzitet Singidunum, Beograd, Srbija
}

\begin{abstract}
Apstrakt:
U savremenim tržišnim uslovima primetno je širenje koncepta javnog interesa, odnosno jačanje značaja poslovanja javnih organizacija. Pored društvenog značaja javne organizacije imaju strateški i politički značaj za jednu zemlju. Zbog toga je od presudne važnosti za društvo da takve organizacije uspešno posluju. Tržišna privreda u kojoj posluju današnje javne organizacije puna je izazova, opasnosti i promena što od rukovodstva javnih organizacija zahteva formulisanje adekvatne strategije i njene implementacije. U ovom radu je opisan proces strategijskog razvoja Auto-moto Saveza Republike Srpske, od definisanja vizije, misije i strateških ciljeva do uvođenja sistema za merenje učinka. Prevođenje strategijskih u operativne ciljeve omogućeno je uvođenjem projektovanog sistema merenja performansi organizacije i zaposlenih, poznatije pod nazivom nazivom Balanced Scorecard.
\end{abstract}

\section{Ključne reči:}

javna organizacija, strategijsko upravljanje, upravljanje učinkom, Balanced Scorecard.

\section{UVOD}

Danas organizacije posluju u dinamičnoj sredini što dovodi do velikog pritiska na rukovodstvo bez obzira na vlasničku strukturu organizacije. U uslovima stalnih promjena na tržištu rukovodstvo mora da pronađe adekvatan strategijski pravac budućeg razvoja organizacije, što zbog čestih modifikuja predstavlja veliki poslovni izazov.

Namjera je da ovim radom odgovorimo na ključne izazove vezane za današnje poslovanje javnih organizacija, a to su:

- Kako poboljšati poslovanje javne organizacije i dovesti je u stanje društveno odgovorne organizacije;

- Da li je Balanced Scorecard (BSC), kao savremen koncept poboljšanja poslovanja, moguće primeniti u poslovanju javne organizacije.

Opšte je prihvaćen stav da je lakše formulisati strategiju nego je implementirati. Istraživanja ukazuju da organizacije koje koriste BSC kao koncept poboljšanja poslovanja ostvaruju bolje poslovne performanse od konkurencije. Nastanak BSC koncepta mjerenja performansi vezan je za autore Kaplana i Nortona, koji su devedesetih godina prošlog veka došli do zaključka da većina organizacija ne uspijeva adekvatno implementirati strategiju. Njihovo istraživanje je dovelo do univerzalnog okvira koji bi ujedinio sve okvire praćenja performansi (Kaplan \& Norton, 1996). BSC kao sredstvo za poboljšanje poslovanja organizacije nije samo koncept mjerenja performansi organi-

\section{Abstract:}

In modern market conditions, the expansion of the concept of public interest, i.e., strengthening of relevance of public organizations, is quite evident. Besides social significance, public organizations also have considerable strategic and political significance for a country. Hence, it is of vital importance for the society to enable such organizations to operate successfully. The market economy of today's public organizations is full of challenges, risks and changes that require an adequate strategy and its proper implementation by an organization's management. The paper describes the process of strategic development of the Automobile Association of the Republic of Srpska, from determining its vision, mission and strategic goals to introduction of performance management system. Translating strategic into operational objectives was triggered by the introduction of the system measuring an organization's and individual's performances, commonly known as Balanced Scorecard.

\section{Key words:}

public organization, strategic management, performance management, Balanced Scorecard.

zacije nego ga možemo posmatrati kao sredstvo koje povezuje formulisanje strategije sa njenom operacionalizacijom (Kaplan \& Norton, 2010).

Države Balkana koje pretenduju da postanu članice Evropske unije moraju ispuniti uslov da se deo javnih organizacija koje posluju profitabilno na tržištu moraju dovesti u stanje samoodrživosti tj. da mogu ograničeno uživati subvencije od strane države (Ugovor o funkcionisanju EU). Drugu vrstu javnih organizacija koje posluju neprofitabilno i stoga su na teretu budžeta, države moraju dovesti u stanje društveno odgovornih organizacija koje u potpuosti zadovoljavaju zahtjeve osnivača (Vlada) i potrebe klijenata (građana).

U ovom radu je prikazano viđenje budućeg razvoja Automoto Saveza Republike Srpske (AMS RS), kao organizacije od javnog interesa, kroz primjenu BSC kao savremenog koncepta poboljšanja poslovanja organizacije.

\section{O AUTO-MOTO SAVEZU RS}

AMS RS je osnovan 1993. godine, kao organizacija koja će $\mathrm{u}$ toku građanskog rata u $\mathrm{BiH}$ djelovati na teritoriji Republike Srpske, nastavljajući tradiciju bivšeg Auto-moto saveza Bosne i Hercegovine, sa sjedištem organizacije u Banja Luci. Danas u sastavu AMS RS djeluje 40 Auto-moto društava (AMD), kao posebnih organizacionih jedinica raspoređenih na čitavoj teritoriji Republike Srpske. 
Položaj i ovlaštenje Auto-moto saveza Republike Srpske uređeni su Zakonom o ovlašćenjima AMS RS (Službeni glasnik Republike Srpske, 2009). U skladu sa svojim statutarnim odredbama AMS RS obavlja sljedeće djelatnosti:

- Tehnička pomoć vozačima na putevima;

- Distribucija obrazaca za izdavanje međunarodnih vozačkih dokumenata;

- Poslovi iz oblasti bezbjednosti drumskog saobraćaja;

- Prikupljanje i saopštavanje informacija o stanju na putevima;

- Druge djelatnosti povjerene od strane nadležnih organa.

\section{RAZVOJ STRATEGIJE AMS RS}

Prije formulisanja razvojne strategiju AMS RS urađena je analiza okruženja organizacije, kao proces nadgledanja (kontrole) da bi se identifikovale sadašnje i buduće šanse i prijetnje koje mogu uticati na sposobnost organizacije za postizanje njenih ciljeva (Mašić, 2009). Analiza sredine obuhvata analizu eksterne (posredno i konkurensko okruženje AMS RS) i analizu interne sredine (izvori i sposobnost preduzeća).

$\mathrm{Za}$ analizu posrednog okruženja korišćena je PEST analiza (politički, ekonomski, društveni i tehnološki okvir). Za analizu konkurentnog okruženja korišćen je Porterov model 5 sila (faktora grane), dok je za analizu interne sredine korišten je Porterov lanac vrijednosti (Mašić, 2009). Procjena okruženja je potom sumirana SWOT analizom (Slika 1), koja omogućava rukovodstvu AMS RS da prepozna sve prijetnje i mogućnosti koje dolaze iz okruženja, a sa druge strane snage i slabosti, kao interne faktore organizacije.

\begin{tabular}{|c|c|}
\hline SNAGE & SLABOSTI \\
\hline $\begin{array}{l}\text { - Dobar imidž u javnosti } \\
\text { - Stabilno finansiranje } \\
\text { - Sigurno tržište } \\
\text { - Razvijena distribucija } \\
\text { - Investiciona ulaganja }\end{array}$ & $\begin{array}{l}\text { Nezastupljenost u među- } \\
\text { narodnim udruženjima } \\
\text { - Zavisnost finansiranja od } \\
\text { politike } \\
\text { - Nerazvijene srodne dje- } \\
\text { latnosti } \\
\text { - Slaba opremljenost po- } \\
\text { družnica (AMD) }\end{array}$ \\
\hline PRILIKE & PRETNJE \\
\hline $\begin{array}{l}\text { Osvajanje prostora tržiš- } \\
\text { nog učešća } \\
\text { - Rast broja registrova- } \\
\text { nih vozila (potencijalni } \\
\text { klijenti) } \\
\text { - Proširenje poslovne ak- } \\
\text { tivnosti na druge srodne } \\
\text { djelatnosti } \\
\text { - Uvođenje međunarodnih } \\
\text { standarda kvaliteta }\end{array}$ & $\begin{array}{l}\text { - Ukidanje polobudžetskog } \\
\text { finansiranja } \\
\text { - Nestabilna politička- } \\
\text { ekonomsko-socijalna } \\
\text { situacija u zemlji } \\
\text { - Konkurencija (BIHAMK, } \\
\text { HAK) } \\
\text { - Uvođenje međunarodnih } \\
\text { standarda kvaliteta }\end{array}$ \\
\hline
\end{tabular}

\section{Slika 1. SWOT analiza AMS RS}

Nakon identifikacije kritičnih faktora koji utiču na poslovanje, definisani su misija, vizija i strategijski ciljevi organizacije. Misija AMS RS, kao svrha postojanja koja daje identitet organizaciji (Mašić, 2009), definisana je kroz potrebu svojih članova (vozača) za kvalitetno pružanje usluga pomoći na putu, kao i podizanje saobraćajne i tehničke kulture svih učesnika u saobra- ćaju. Vizija, kao dalekosežni cilj kome teži organizacija (Mašić, 2009), jeste da AMS RS postane lider na cijeloj teritoriji BiH u pogledu poslovanja, ostvarujući visok kvalitet usluga za svoje članove i sve ostale potencijalne korisnike usluga.

Strategija razvoja je pretvorena u grupe operativnih ciljeva kojima AMS RS planira da usmeri svoje aktivnosti radi ispunjenja misije i vizije organizacije. Izdvojena su tri pravca budućeg razvoja poslovanja i postavljeni operativni ciljevi organizacije.

1. Povećanje konkurentnosti u odnosi na druge organizacije sa srodnom djelatnošću:

- Izgradnja objekata AMD i opremanje opremom i voznim parkom;

- Na teritoriji Federacije BiH poslove mogu da obavljaju partneri u ime AMS RS

- Razvoj ljudskih resursa;

- Dobra saradnja sa medijima, Vladom i javnošću RS.

2. Tržišna profitabilnost kao preduslov za finansijsku i političku nezavisnost budućeg poslovanja:

- Smanjenje troškova poslovanja

- Formiranje privrednog društva sa službom „Pomoć i informacije na putu“;

- Osnivanje osiguravajuće kuće, samostalno ili sa potencijalnim partnerom;

- Formiranje ostalih privrednih društva iz srodne djelatnosti.

3. Stvaranje dobrog imidža kod Vlade i javnosti RS i BiH:

- Formiranje školskih saobraćajnih sekcija;

- Provođenje preventivnih tehničkih pregleda vozila;

- Izrada i distribucija ilustrovanih letaka.

\section{UPOTREBA BSC U PRIMENI STRATEGIJE AMS RS}

Koncept BSC se bazira na praćenju performansi poslovnih procesa koji direktno utiču na uspjeh realizacije razvojne strategije organizacije. Cilj BSC je da rukovodioci na svim nivoima imaju prikaz stanja u organizaciji, što im omogućava da svoje djelovanje usmjeravaju na kritična područja u sistemu poslovanja organizacije.

Razvojem koncepta BSC došlo se do kombinovanja mjerila koja proizilaze iz strategije preduzeća. Prema konceptu BSC ciljevi i mjerila se izvode iz vizije i strategije organizacije, a definišu se kroz četiri perpektive, kojima se adresuju interesi vlasnika, kupaca i zaposlenih: finansije, kupci, interni procesi i učenje i razvoj (Kaplan \& Norton, 2010). Strategijskim planom razvoja postavljeni su operativni ciljevi budućih performansi AMS RS iz perspektive povećanja konkurentnosti organizacije, tržišne profitabilnosti i stvaranja dobrog imidža (Tabela 1).

Obzirom da su predstavljeni operativni ciljevi, za procjenu performansi sjedišta i organizacionih jedinica AMS RS predviđene su ocjene postignutog rezultata od 1 do 5 za svaku mjeru uspeha Tabela 2).

\begin{tabular}{|c|c|}
\hline Ostvarenje (\%) & Ocjena \\
\hline Ispod 60 & 1 \\
\hline $61-70$ & 2 \\
\hline $71-80$ & 3 \\
\hline $81-90$ & 4 \\
\hline $91-100$ & 5 \\
\hline
\end{tabular}

Tabela 2. Skala za mjerenje i procjenu performansi operativnih ciljeva AMS RS 


\begin{tabular}{|c|c|c|c|}
\hline Cilj & Mjera uspeha & Formula za izračunavanje & $\begin{array}{c}\text { Periodičnost } \\
\text { mjerenja }\end{array}$ \\
\hline \multicolumn{4}{|c|}{ Konkurentnost organizacije } \\
\hline Prevoz vozila na teritoriji RS i BiH & $\begin{array}{l}\text { Sigurno i na vrijeme prevoziti } \\
\text { havarisana vozila i putnike }\end{array}$ & $\begin{array}{l}\text { 15\% povećanje broja prevoza po AMD } \\
\text { (10 intervencija) }\end{array}$ & Mjesečno \\
\hline $\begin{array}{l}\text { Vremenski period dolaska na inter- } \\
\text { venciju }\end{array}$ & $\begin{array}{l}\text { Smanjiti vremenski period dolaska na } \\
\text { intervenciju }\end{array}$ & $\begin{array}{l}30 \% \text { povećanje efikasnosti (vreme } \\
\text { intervencije } 40 \mathrm{~min} \text { ) }\end{array}$ & Mjesečno \\
\hline Povećanje broja preventivnih akcija & Preventivni tehnički pregled vozila & 480 vozila po AMD & Godišnje \\
\hline \multirow{2}{*}{ Obuka zaposlenih na nivou AMS RS } & $\begin{array}{l}\text { Obuka zaposlenih u Službi SPI u radu } \\
\text { sa klijentima }\end{array}$ & $\begin{array}{l}50 \% \text { obučenog osoblja ( } 20 \text { vozača i } 20 \\
\text { administratora) }\end{array}$ & Godišnje \\
\hline & $\begin{array}{l}\text { Obuka rukovodilaca AMS RS u } \\
\text { poslovnim veštinama }\end{array}$ & $\begin{array}{l}50 \% \text { obučenog osoblja ( } 22 \text { rukovo- } \\
\text { dioca) }\end{array}$ & Godišnje \\
\hline \multicolumn{4}{|c|}{ Tržišna profitabilnost } \\
\hline $\begin{array}{l}\text { Smanjenje troškova prevoza (plaćanje } \\
\text { prema AMD) }\end{array}$ & Satelitsko praćenje vozila & $\begin{array}{l}\text { 20\% smanjenja fiktivne kilometraže } \\
(36.000 \mathrm{~km})\end{array}$ & Godišnje \\
\hline Smanjenje troškova ordžavanja vozila & $\begin{array}{l}\text { Prebaciti kontrolu ispravnosti i } \\
\text { održavanja vozila na AMD }\end{array}$ & $100 \%$ smanjenje troškova & Godišnje \\
\hline $\begin{array}{l}\text { Smanjenje troškova po osnovu ličnih } \\
\text { dohodaka }\end{array}$ & $\begin{array}{l}\text { Sistematizacija radnih mjesta u } \\
\text { sjedištu AMS RS }\end{array}$ & $20 \%$ smanjenje radne snage & Godišnje \\
\hline $\begin{array}{l}\text { Formiranje prodavnice auto delova } \\
\text { (srodne delatnosti) }\end{array}$ & $\begin{array}{l}\text { Formirati prodavnice u } 50 \% \text { baznih } \\
\text { centara }\end{array}$ & 3 prodavnice auto delova & Godišnje \\
\hline \multicolumn{4}{|c|}{ Stvaranje dobrog imidža } \\
\hline Zadžati povoljan status na tržištu & $\begin{array}{l}\text { Zadržati polubudžetski način finan- } \\
\text { siranja }\end{array}$ & $\begin{array}{l}100 \% \text { ispunjenje plana budžeta } \\
(2.800 .000 \mathrm{KM})\end{array}$ & Godišnje \\
\hline \multirow{2}{*}{ Povećanje broja preventivnih akcija } & $\begin{array}{l}\text { Formirati školske saobraćajne sekcije } \\
\text { preko AMD }\end{array}$ & $\begin{array}{l}480 \text { saobraćajnih sekcija na teritoriji } \\
\text { RS }\end{array}$ & Godišnje \\
\hline & $\begin{array}{l}\text { Izrada i podjela ilustrovanih letaka u } \\
\text { vezi preventivnih akcija }\end{array}$ & 200.000 učesnika u saobraćaju & Godišnje \\
\hline Omasoviti članstvo u AMS RS & Povećanje broja članova AMS RS & $\begin{array}{l}\text { 25\% povećanje broja članova (ukupno } \\
10.000 \text { članova) }\end{array}$ & Polugodišnje \\
\hline $\begin{array}{l}\text { Poboljšati vidljivost AMS RS u medi- } \\
\text { jima RS }\end{array}$ & $\begin{array}{l}\text { Prisutnost u pisanim i e-medijima RS } \\
\text { i BiH }\end{array}$ & $\begin{array}{l}\text { 100\% pokrivenost vodećih pisanih i } \\
\text { e- medija }\end{array}$ & Kvartalno \\
\hline
\end{tabular}

Tabela 1. Primjer operativnih ciljeva AMS RS

Bodovnom ocjenom svake mjere uspeha procjenjuje se prosječan uspjeh svake organizacione jedinice AMS RS. Na taj način učinak zaposlenih omogućava rangiranje organizacionih jedinica kao uslov za raspodjelu finansijskih sredstava na osnovu postignutih rezultata. Većinska raspodela finansijskih sredstava se trenutno utvrđuje na osnovu regionalizacije, proporcionalno spram dužine puteva i broja registrovanih vozila na podučju AMD, što dovodi do inertnosti u poslovanju. Primenom prikazanog modela BSC, raspodela finansijskih sredstava može biti korigovana na osnovu performansi svake organizacione jedinice, po Pravilniku o finansiranju i odluci koji utvrđuje Upravni odbor AMS RS.

\section{ZAKLJUČAK}

Osnovna prepreka u razvoju domaćih organizacija iz javnog sektora jeste nespremnost rukovodilaca da primjenjuju savremene koncepte poboljšanja poslovanja, čija je primjena neophodna u današnjoj turbulentnoj sredini. Najveći problem se javlja u implementaciji jer se samo $10 \%$ formulisanih strategija uspešno primeni u organizacijama (Charan, 1999). Zbog toga je na početku ovog projekta obezbeđena podrška izvršnog rukovodstva AMS RS u pripremi na implementaciji BSC modela $\mathrm{u}$ pojedinim organizacionim jedinicama.

Primjena modela BSC u AMS RS započela je identifikacijom ključnih faktora poslovanja i definisanjem misije, vizije i strategijskih ciljeva organizacije. Prevođenjem strategijskih u operativne ciljeve moguća je promena prirode poslovanja AMS
RS u budućnosti, bez subvencije od strane države. Time se u potpunosti ostvaruje princip modela BSC kojim se usklađuje učinak organizacionih jedinica sa strategijom i motivišu zaposleni da se angažuju na sprovođenju operativnih ciljeva organizacije. Dosadašnji rezultati u implementaciji na primjeru AMD Doboj pokazuju da se BSC model može uspešno primeniti u javnim organizacijama, bez obzira na pravni okvir poslovanja (tržišno ili budžetksi).

\section{LITERATURA}

Charan R. (1999). Why CEOs fail, Fortune Magazine; June 1999. Preuzeto sa http://www.fortune.com/fortune/print/0,15935,374594,00. html

Evropska unija. (2010). Ugovor o funkcionisanju EU. Preuzeto sa www.europa.eu

Kaplan, R., \& Norton, D. (1996). The Balanced Scorecard: Translating Strategy into Action. Boston, MA: Harward Business School Press.

Kaplan, R., \& Norton, D. (2010). Premija za uspeh. Povezivanje strategije sa operacijama radi sticanja konkurentske prednosti. Beograd: FEFA.

Mašić, B. (2009). Strategijski menadžment. Beograd: Univrezitet Singidunum.

Službeni glasnik Republike Srpske. (2009). Zakon o izmjenama i dopunama Zakona o penzijskom i invalidskom osiguranju. Službeni glasnik Republike Srpske br. 01/09 http://www. slglasnik.org/ 